\title{
A SAÚDE MENTAL DE MÉDICOS E A PANDEMIA COVID-19
}

\section{THE MENTAL HEALTH OF DOCTORS AND THE COVID-19 PANDEMIC}

\author{
Luciano Pereira Zille \\ Faculdade de Ciências Médicas de Minas Gerais - FELUMA \\ luciano.zille.prof@gmail.com \\ Jaqueline dos Santos Teles \\ Faculdade de Ciências Médicas de Minas Gerais - FELUMA \\ jackteles@yahoo.com.br
}

Submissão: $16 / 07 / 2021$

Aprovação: 02/12/2021

Fast-track do Congresso da ISMA/BR (International Stress Management Association)

\begin{abstract}
RESUMO
Objetivou descrever o risco de adoecimento mental de médicos que atuam em serviços de saúde, considerando a Pandemia COVID-19, tendo como referência a Psicodinâmica do Trabalho. A pesquisa foi de natureza descritiva, abordagem quantitativa, com população de 54.393 médicos atuantes no estado de Minas Gerais, com amostra calculada de 401 sujeitos. A análise se deu por meio da estatística uni e bivariada. Os resultados apontaram, em média, de forma crítica a maioria dos construtos avaliados: organização e condições de trabalho, relações sócioprofissionais, custos físico e afetivo e esgotamento profissional, sendo que o construto custo cognitivo se manifestou de forma grave. Os construtos satisfatórios foram: realização profissional, liberdade de expressão, reconhecimento pelo trabalho, danos psicológicos e sociais e as estratégias de defesa. Ao relacionar os riscos de adoecimento com as variáveis demográficas e funcionais do estudo, concluiu-se que os médicos que vivem com o cônjuge e aqueles que têm maior experiência profissional vêm enfrentando de forma mais satisfatória as situações adversas de trabalho neste período de pandemia.
\end{abstract}

Palavras-chave: Riscos de adoecimento mental. Psicodinâmica do trabalho. Pandemia Covid $-19$.

\begin{abstract}
It aimed to describe the risk of mental illness of physicians working in health services, considering the COVID-19 pandemic, using the Psychodynamics of Work as a reference. The research was descriptive in nature, with a quantitative approach, with a population of 54,393 doctors working in the state of Minas Gerais, with a calculated sample of 401 subjects. The analysis was performed using uni and bivariate statistics. The results showed, on average, most of the constructs evaluated critically: organization and working conditions, socio-professional relationships, physical and emotional costs and professional exhaustion, and the cognitive cost construct was severely manifested. The satisfactory constructs were: professional fulfillment, freedom of expression, recognition for work, psychological and social harm and defense
\end{abstract}


strategies. By relating the risks of illness with the demographic and functional variables of the study, it was concluded that physicians who live with their spouse and those who have more professional experience have been dealing more satisfactorily with adverse work situations in this period of pandemic.

Keywords: Risks of mental illness. Psychodynamics of work. Covid Pandemic -19 .

\section{Introdução}

O trabalho é o alicerce da vida humana e se constitui em mecanismo de interseção entre a natureza e o homem na sua formação, agindo entre o inconsciente e o âmbito social. Permite ao indivíduo afirmar sua identidade e se torna ponto central da existência humana, tanto no plano pessoal quanto social. Entretanto, sabe-se que a dinâmica intersubjetiva construída entre o trabalhador e o campo social pode resultar em vivências de prazer e também de sofrimento (DEJOURS; ABDOUCHELI; JAYET, 1994).

A vivência de prazer no trabalho é experimentada quando o indivíduo se sente valorizado, reconhecido e quando realiza uma tarefa importante para a organização e para a sociedade (DEJOURS, 2015). Por outro lado, de acordo com Dejours (2011), o sofrimento é inerente ao trabalho, em função da existência de um conflito entre a sistematização e suas normas e as exigências do funcionamento psíquico do indivíduo relacionadas aos seus desejos.

A necessidade inevitável de equilibrar prazer e sofrimento no trabalho é foco da Psicodinâmica do Trabalho. Esse campo de estudo se depara com duas questões principais: compreender os dispositivos necessários ao trabalhador para manter seu equilíbrio mental frente às circunstâncias de trabalho que possam desestruturar seu sistema psíquico e fomentar o uso das estratégias defensivas capazes de transformar sofrimento em prazer.

De acordo com Dejours (2004), as vivências de prazer e sofrimento são inerentes a qualquer profissão e ocorrem nos mais diversos contextos de trabalho. Entretanto, é necessário reconhecer que existem categorias profissionais mais vulneráveis, dentre as quais se incluem os médicos, uma vez que eles convivem com a dor física, emocional e com o limítrofe entre a vida e a morte dos pacientes, além das aflições dos familiares. Portanto, trata-se de uma profissão com grande exposição às condições de pressão relacionadas ao trabalho (PITTA, 2003). Um bom exemplo é a situação ora vivenciada no Brasil com a pandemia COVID-19. Nela, os médicos se deparam com condições precárias de trabalho, insuficiência de equipamentos, escassez de material e pessoal qualificado, além da falta de investimento público e interferência política (DA CUNHA, 2019).

No que se refere a saúde mental no trabalho, a atuação profissional desses indivíduos é marcada pela convivência com a dor física, emocional e com o limítrofe entre a vida e a morte dos pacientes, além das aflições dos familiares. Portanto, trata-se de uma profissão com grande exposição à pressão relacionada ao trabalho (PITTA, 2003) que se intensificou com o agravamento da pandemia (BRASIL, 2020).

Tendo em vista os conteúdos apresentados até então, tem-se como objetivo deste estudo descrever a percepção do risco de adoecimento mental de médicos que atuam em serviços de saúde considerando a COVID-19 no estado de Minas Gerais, tendo como referência a psicodinâmica do trabalho.

Em termos de contribuições, pode-se citar a utilização do Modelo Teórico de Riscos de Adoecimento Mental no Trabalho baseado no ITRA, desenvolvido por Mendes e Ferreira (2007), agregando-se a Escala de Estratégias de Defesa (ZILLE, 2005), concebendo assim, um novo modelo para análise da categoria médica. Dessa forma, ampliam-se os estudos relacionados à saúde mental desta categoria profissional, sobretudo num momento especial onde ocorre a pandemia COVID-19, cuja atuação destes profissionais vem sendo de elevadíssima importância para o seu enfrentamento. 


\section{Referencial Teórico}

A Psicodinâmica do Trabalho foi construída inicialmente com fundamentação na Psicopatologia e evoluiu para o estudo das relações dinâmicas do sofrimento psíquico do indivíduo, área de estudo em que o trabalho exerce importante papel. A expressão "Psicodinâmica do Trabalho" surgiu nos anos 1990, na França, com os trabalhos do médico francês Christophe Dejours. Trata-se de uma abordagem científica, que tem objetivos, princípios, conceitos e métodos particulares para compreender a dinâmica do contexto do trabalho, focando nas vivências de prazer e de sofrimento, bem como nas estratégias defensivas adotadas pelos trabalhadores (DEJOURS, 1992, 1999, 2007).

Inicialmente, Christophe Dejours utilizava o termo Psicopatologia do Trabalho para caracterizar a compreensão e o tratamento das doenças mentais e psicossomáticas de trabalhadores que se encontravam afastados de suas atividades profissionais por razão de patologias. Posteriormente, o foco do estudo passou a ser também os profissionais em exercício pleno de suas funções, com enfoque no prazer e no sofrimento advindo do trabalho. Com isso, um novo termo veio a ser utilizado por expressar melhor o campo de trabalho e pesquisa, ou seja, a "Psicodinâmica do Trabalho" (MÉLOU; et al. 2017).

A Psicodinâmica do Trabalho aborda os processos inconscientes do indivíduo estabelecidos nas suas relações com o trabalho. Ao longo do seu desenvolvimento, passou-se a observar, não apenas a existência de uma síndrome psicopatológica decorrente dos constrangimentos sofridos no trabalho, como acontecia com os problemas físicos, mas, também, a mobilização subjetiva do trabalhador para equilibrar vivências de prazer e sofrimento advindas do trabalho (DEJOURS, 1991).

Quanto ao objetivo da Psicodinâmica do Trabalho, Dejours (2017) afirma que este se refere ao estudo do indivíduo e suas relações com o trabalho e sua forma organizacional, que pode ser determinante para o sofrimento psicológico. $\mathrm{O}$ autor afirma que a organização do trabalho acarreta alterações psicológicas no sujeito, quando se estabelece um choque entre seus desejos pessoais e a forma como a organização considera as expectativas do trabalhador.

Desse modo, os mecanismos de defesas são formas que os trabalhadores encontram de modelar o pensamento, suas ações e sentimentos, de modo que seja possível vislumbrar alguma compensação para justificar e tolerar o sofrimento. Quando construída pelo coletivo, essas estratégias são baseadas em acordos implícitos entre os trabalhadores, tendo como objetivo diminuir o sofrimento e agir como uma estratégia de proteção individual e/ou coletiva (DEJOURS, 1999; MENDES, 2007).

A exigência cada vez mais intensa da organização para ampliação da produção tem provocado consequências importantes à saúde mental do trabalhador (MÉLOU et al., 2017). Nessa direção, as pesquisas na vertente da Psicodinâmica do Trabalho surgem como uma possibilidade efetiva para analisar os indivíduos em relação aos riscos à sua saúde no trabalho. Para esse fim, Mendes e Ferreira (2007) desenvolveram um instrumento para identificar os efeitos do trabalho no processo de adoecimento dos trabalhadores. Esse instrumento foi denominado de Inventário sobre Trabalho e Riscos de Adoecimento (ITRA), tendo sido utilizado na coleta de dados desta pesquisa, juntamente com a Escala de Avaliação de Atuação das Estratégias de Defesa desenvolvida e validada por Zille (2005).

\subsection{Indicadores críticos de risco de adoecimento no trabalho}

A percepção dos médicos pesquisados acerca do risco de adoecimento mental a que estão submetidos foi avaliada a partir de dois instrumentos: o Inventário sobre Trabalho e Riscos de Adoecimento (ITRA) (MENDES; FERREIRA, 2007) e a Escala de Avaliação da Atuação das Estratégias de Defesa (ZILLE, 2005). 
O ITRA é um Instrumento Auxiliar de Diagnóstico de Indicadores Críticos no Trabalho, desenvolvido e validado por Ferreira e Mendes (2003), revalidado após adaptações por Mendes et al., (2005) e novamente submetido à revalidação por Ferreira e Mendes (2007). Essa última versão foi utilizada para a coleta dos dados deste estudo. Busca investigar o contexto de trabalho e suas exigências (físicas, cognitivas e afetivas), danos relacionados ao trabalho, vivências de prazer e sofrimento e os riscos de adoecimento (MENDES; FERREIRA, 2007).

A Escala de Avaliação da Atuação das Estratégias de Defesa, por sua vez, foi desenvolvida e validada por Zille (2005) e teve por objetivo identificar as estratégias utilizadas para minimizar e/ou eliminar os riscos de adoecimento mental.

Os construtos e seus respectivos conceitos baseado em Mendes e Ferreira (2007) e Zille (2005), foram sintetizados por meio do QUADRO 1, apresentado a seguir.

Quadro 1 - Detalhamento das escalas e dos construtos utilizados no estudo

Escala de Avaliação do Contexto de Trabalho (alfa de Cronbach acima de 0,70)

- Organização do trabalho: "Divisão e conteúdo das tarefas, normas, controles e ritmos de trabalho"

- Condições de trabalho: "Qualidade do ambiente físico, posto de trabalho, equipamentos e material

disponível para execução do trabalho".

- Relações sócioprofissionais:"Modos de gestão do trabalho, comunicação e interação profissional"

\section{Escala de Custo Humano no Trabalho (alfa de Cronbach acima de 0,84)}

- Custo físico: "Dispêndio físiológico e biomecânico imposto ao trabalhador pelas características do contexto de produção".

- Custo cognitivo: "Dispêndio intelectual para aprendizagem, resolução de problemas e tomada de decisão no trabalho".

- Custo afetivo: "Dispêndio emocional, sob a forma de reações afetivas, sentimentos e de estados de humor".

Escala de Indicadores de Prazer e Sofrimento no Trabalho (alfa de Cronbach acima de 0,80)

- Prazer - Realização profissional: "Vivência de gratificação profissional, orgulho e identificação com o trabalho que faz".

- Prazer - Liberdade de expressão: "Vivência expressão, vivência de liberdade para pensar, organizar e falar sobre o seu trabalho".

- Sofrimento - Esgotamento profissional: "Vivência de frustração, insegurança, inutilidade, desgaste e estresse no trabalho".

- Sofrimento - Falta de reconhecimento: "Vivência de injustiça, indignação e desvalorização pelo não reconhecimento do trabalho".

Escala de Danos Relacionados ao Trabalho (alfa de Cronbach acima de $\mathbf{0 , 8 8}$ )

- Dano físico: "Dores no corpo e distúrbios biológicos".

- Dano psicológico: "Sentimentos negativos em relação a si mesmo e à vida em geral".

- Dano social: "Isolamento e dificuldades nas relações familiares e sociais".

Escala de Avaliação da Atuação das Estratégias de Defesa (alfa de Cronbach acima de 0,83)

- Estratégias de defesa: estraégias utilizadas para minimizar e/ou eliminar os riscos de adoecimento mental (ZILLE, p. 168-172, 2005).

Fonte: Elaborado pelos autores (2020) com base em Ferreira e Mendes (2007, p. 115-125) e Zille (2005, p. 168172 ). 


\subsection{Adoecimento no trabalho de profissionais médicos}

Vários são os fatores relacionados ao adoecimento de profissionais que exercem a medicina. Um dos mais importantes refere-se ao número de vínculos empregatícios e a quantidade de horas semanais trabalhadas. Nesse contexto, Maciel et al. (2010), em pesquisa com 7.008 médicos no estado do Ceará, apuraram que 53,5\% dos pesquisados possuíam entre 2 a 4 vínculos de trabalho e $0,6 \%$, entre 11 e 20 vínculos; $51,9 \%$ tinham uma carga horária semanal de trabalho acima de 40 horas; e 27,0\% mantinham vínculos em mais de um município. Os autores concluíram que o acúmulo de vínculos e de horas de trabalho constitui-se fator importante de desgaste na saúde dos médicos, podendo contribuir para o adoecimento físico e mental destes profissionais.

Da Cunha (2019) realizou estudo com o objetivo de descrever e analisar vivências de prazer e sofrimento de 10 médicos oncologistas na cidade de Belo Horizonte/MG. Os resultados evidenciaram vivências de prazer que se alicerçam na liberdade de expressão, no reconhecimento profissional, na cura de pacientes, enquanto o sofrimento era decorrente da falta de recursos necessários ao trabalho, no convívio diário com a morte dos pacientes e na gestão de conflitos nos diversos contextos de trabalho.

Lai et al. (2020) avaliaram a saúde mental de 1.257 profissionais de saúde em 34 hospitais que tratavam de pacientes expostos a COVID-19 na China. Proporção significativa $634(50,4 \%)$ dos participantes experimentou sintomas de ansiedade, 560 (44,6\%) depressão, 427 (34\%), insônia e mais de 70\% relataram sofrimento psicológico importante. As fontes de angústia incluíram sentimentos de vulnerabilidade, preocupações com a saúde própria, possibilidade de disseminação do vírus, impactos na saúde da família e preocupações com o isolamento social.

A Faculdade de Medicina da Universidade de Brasília e do Hospital Universitário de Brasília avaliaram o comportamento de médicos residentes que estiveram envolvidos no atendimento de pacientes com suspeita de COVID-19. A pesquisa indicou que, entre os fatores analisados (ansiedade, insônia, depressão e insônia), a ansiedade foi o sintoma que mais afetou os médicos $(41,7 \%) ; 25 \%$ dos médicos residentes afirmaram já ter considerado trocar de especialidade devido à pandemia; $(83,3 \%)$ dos pesquisados disseram que a qualidade geral do sono estava ruim; e (75\%) manifestaram sonolência diurna (BRASIL, 2020).

Lu et al. (2020) publicaram estudo que retratou a avaliação da saúde mental de 2.042 médicos chineses atuantes na linha de frente do combate a Pandemia COVID-19. Os resultados mostraram que 70,6\% dos médicos apresentaram medo moderado e grave, 22,6\% apresentaram ansiedade leve a moderada e 2,9\% apresentaram ansiedade grave. Ainda, 11,8\% da equipe médica pesquisada apresentou depressão leve a moderada e $0,3 \%$ depressão grave.

\subsection{A pandemia covid-19}

Em dezembro de 2019, um novo tipo de pneumonia de origem desconhecida foi identificado em pacientes que haviam frequentado o mercado Wuhan de frutos do mar, em Wuhan, província de Hubei, na China. Após sequenciamento genético, identificou-se que a doença que acometia os enfermos era causada por um novo tipo de Coronavírus (GREENLAND; et al., 2020). Coronavírus é o nome de uma família de vírus que causa infecções respiratórias e que possui, em sua superfície, protuberâncias similares a "espinhos" que lhe conferem aparência semelhante à uma coroa - corona em espanhol (BRASIL, 2020).

Da China, o novo Coronavírus se espalhou rapidamente pelo mundo, a partir de viajantes que, provenientes desse local, retornaram a seus países de origem (VELAVAN; MEYER, 2020). Em março de 2020, a Organização Mundial de Saúde (OMS) (WHO, 2020) decretou situação de pandemia em função dos números crescentes de casos da doença e das 
mortes a ela atribuídas no mundo. Dados de 10/10/2020 indicavam ocorrência de 1.070.355 mortes e 37.109.851 casos confirmados da doença em 235 países.

No Brasil, o primeiro caso suspeito de corona vírus foi identificado em 26/02/2020 e novas ocorrências vêm crescendo rapidamente (CRODA; et al., 2020). Em Minas Gerais, o primeiro caso foi registrado em 4 de março de 2020 (MINAS GERAIS, 2020c). Desde então, o número de infectados vem crescendo exponencialmente (MINAS GERAIS, 2020a). Em 20 de março, o Estado decretou situação de calamidade pública em razão da epidemia causada pelo novo Coronavírus.

No combate a essa nova doença, os médicos estão entre os profissionais que se encontram na linha de frente. Estão submetidos à elevada carga de trabalho (REGO; PALÁCIOS, 2020), altos níveis de estresse e de depressão (ZHANG; et al., 2020) e ao sentimento de incapacidade profissional que a eles se apresenta diante de pacientes com quadros graves ou irreversíveis da doença (CHEN; et al., 2020). Somado a esses fatores, a saúde mental dos médicos se deteriora, diante da possibilidade de contaminação pela doença, em função da escassez de equipamentos de proteção; dificuldade em lidar com pacientes doentes que se recusam a adotar o tratamento proposto; da possibilidade de levar o vírus para dentro de suas casas e ao isolamento familiar a que muitos profissionais se submetem para evitar que isso aconteça (CHEN; et al., 2020); e diante da sensação de serem repetidamente exigidos quanto à tomada de decisões que podem resultar na vida ou na morte dos enfermos (REGO; PALÁCIOS, 2020).

\section{Método}

Esta pesquisa classifica-se como descritiva, na medida em que buscou descrever a percepção do risco de adoecimento mental de médicos que atuam em serviços de saúde considerando a COVID-19 no estado de Minas Gerais, tendo como referência a psicodinâmica do trabalho.

A população do estudo envolveu 54.393 médicos, com amostra composta por 401 sujeitos, calculada com base em Barnett (1991), considerando erro amostral de $5 \%$ ( $\mathrm{p}<0,05)$.

Para coleta dos dados foram utilizados o ITRA e a Escala de Avaliação de Atuação das Estratégias de Defesa. Essa última foi revalidada neste estudo segundo critérios propostos por Hair, Anderson, Tatham e Black (2005) e Mesquita (2010), quais sejam: coeficiente de correlação de Pearson entre os indicadores (maioria superior a 0,30), cargas fatoriais (superiores a 0,700), comunalidade (superiores a 0,600), alfa de Cronbach $(0,826)$, Kaiser Meyer Olkin $(\mathrm{KMO}=0,743)$ e porcentagem de variância explicada $(60,0 \%)$. Esses resultados indicaram a adequação da mencionada Escala ao ambiente de atuação dos médicos.

O questionário utilizado na coleta de dados foi formatado eletronicamente e enviado aos médicos por e-mail e/ou por mensagem do aplicativo WhatsApp e disponibilizado no site do Sindicato dos Médicos de Minas Gerais. Os dados dos médicos foram obtidos a partir de consulta realizada junto ao site do CRM/MG, planos de saúde, áreas de recursos humanos de hospitais e clínicas médicas privadas e Sistema Único de Saúde (SUS) no estado de Minas Gerais.

A análise de dados foi realizada por meio da estatística descritiva. Inicialmente calculouse, para cada construto, um indicador ancorado na média de seus respectivos indicadores. A citada média foi avaliada a partir de medidas de tendência central (média) e de variabilidade (desvio padrão, coeficiente de variação, mínimo e máximo da escla). Em seguida, os respondentes foram classificados em diferentes níveis de manifestação em relação aos construtos avaliados, conforme critérios constantes da TAB. 1, apresentada a seguir. 
Tabela 1 - Parâmetros para análise dos indicadores de risco de adoecimento

\begin{tabular}{|c|c|c|c|c|c|}
\hline \multirow{2}{*}{ Construtos } & \multirow{2}{*}{ Escala } & \multicolumn{4}{|c|}{ Níveis } \\
\hline & & \multirow[t]{2}{*}{ Grave } & \multicolumn{2}{|c|}{ Crítico } & Satisfatório \\
\hline \multicolumn{5}{|l|}{ Contexto de trabalho ${ }^{1}$} & \\
\hline $\begin{array}{l}\text { Organização de trabalho } \\
\text { Condições de trabalho } \\
\text { Relações de trabalho }\end{array}$ & 1 a 5 & Abaixo de 2,29 & \multicolumn{2}{|c|}{ Entre 2,3 a 3,69} & Acima de 3,7 \\
\hline \multicolumn{6}{|c|}{ Custo humano no trabalho } \\
\hline $\begin{array}{l}\text { Custo físico } \\
\text { Custo cognitivo } \\
\text { Custo afetivo }\end{array}$ & 1 a 5 & \multirow[t]{2}{*}{ Maior que 3,7} & \multicolumn{2}{|c|}{ Entre 2,30 e 3,69} & $\begin{array}{c}\text { Abaixo de } \\
2,29\end{array}$ \\
\hline \multicolumn{5}{|l|}{ Vivência de prazer } & \\
\hline $\begin{array}{l}\text { Realização profissional } \\
\text { Liberdade de expressão }\end{array}$ & \multirow[t]{2}{*}{0 a 6} & \multirow[t]{2}{*}{ Abaixo de 2,0 } & \multicolumn{2}{|c|}{ Entre 2,1 e 3,9} & Acima de 4,0 \\
\hline \multicolumn{4}{|l|}{ Vivências de sofrimento ${ }^{2}$} & & \\
\hline $\begin{array}{l}\text { Esgotamento profissional } \\
\text { Falta de reconhecimento }\end{array}$ & 0 a 6 & Acima de 4,0 & \multicolumn{2}{|c|}{ Entre 2,1 e 3,9 } & Abaixo de 2,0 \\
\hline \multirow[b]{2}{*}{ Construtos } & \multirow[b]{2}{*}{ Escala } & \multicolumn{4}{|c|}{ Níveis } \\
\hline & & $\begin{array}{c}\text { Presença de doenças } \\
\text { ocupacionais }\end{array}$ & Grave & Crítico & Suportável \\
\hline \multicolumn{6}{|c|}{ Danos relacionados ao trabalho } \\
\hline $\begin{array}{l}\text { Dano físico } \\
\text { Dano psicológico } \\
\text { Dano social }\end{array}$ & 0 a 6 & Acima de 4,1 & $\begin{array}{c}\text { Entre } 3,1 \mathrm{e} \\
4,0\end{array}$ & $\begin{array}{c}\text { Entre } 2,0 \mathrm{e} \\
\quad 3,0\end{array}$ & Abaixo de 1,9 \\
\hline \multirow{2}{*}{ Construtos } & \multirow{2}{*}{ Escala } & \multicolumn{4}{|c|}{ Níveis } \\
\hline & & Ausência & Moderado & Intenso & Muito intenso \\
\hline Estratégias de defesa & & & & & \\
\hline Estratégias de defesa & 1 a 5 & Menor que 2,49 & $\begin{array}{c}\text { Ente } 2,49 \mathrm{e} \\
3,17\end{array}$ & $\begin{array}{c}\text { Entre } 3,18 \\
\text { e } 3,86\end{array}$ & 3,87 e acima \\
\hline
\end{tabular}

Nota 1: Os indicadores da dimensão contexto de trabalho foram invertidos para melhor interpretação dos resultados. Dessa forma, quanto maior o indicador obtido pelo pesquisado, melhor é seu contexto de trabalho.

Nota 2: A definição dos níveis relacionados às estratégias de defesa foi realizada considerando os valores de média $(2,49)$ e de desvio padrão $(0,69)$ identificados nesta pesquisa, conforme critério utilizado no ITRA.

Fonte: Elaborado pelos autores (2020) com base em Mendes e Ferreira (2007) e Zille (2005).

\section{Resultados e Discussões}

A maioria dos médicos participantes da pesquisa realizou atendimento a pacientes com queixa ou em tratamento da COVID-19 (84,0\%); é do gênero feminino $(54,1 \%)$; tem entre 26 e 35 anos $(37,2 \%)$; é casada ou vive com cônjuge (54,4\%). Em relação a escolaridade, a maior parte dos respondentes possui residência médica $(88,2 \%)$, ao passo que apenas $10,2 \%$ tem mestrado e $1,5 \%$, doutorado.

Analisando-se o tempo de atuação como médico, 52,6\% praticam a medicina há mais de 15 anos. Aqueles que exercem a profissão há mais de 6 anos representam 87,5\%. Portanto, é possível afirmar que os médicos pesquisados possuem vivência significativa na profissão. Quanto ao número de serviços em que trabalham como médico, 53,4\% responderam que trabalham em 3 locais diferentes, sendo os mais citados o hospital público $(28,4 \%)$ e o consultório particular $(24,6 \%)$. Em relação ao tipo de contrato mantido com o principal serviço, a maioria dos médicos $(37,9 \%)$, indicou ser autônomo. O trabalho autônomo é característico da profissão médica, visto que esses profissionais optam por manter clínica própria ou por realizar plantões esporádicos em instituições de saúde (GRACINO et al., 2016).

A distribuição dos pesquisados por horas semanais totais trabalhadas indicou que $55,4 \%$ laboram entre 61 e 80 horas semanais. Esse dado mostra a intensiva carga de trabalho destes profissionais que, somada a tensão gerada pelo atendimento aos pacientes com COVID-19 ou suspeita, torna-se uma das causas que contribui para a tensão excessiva e as manifestações de 
estresse no trabalho destes profissionais, contribuindo para a ocorrência de riscos de adoecimento mental.

Com relação aos hábitos de vida, $10,5 \%$ dos médicos afirmaram ter o hábito de fumar e $63,1 \%$ indicaram que consomem bebida alcoólica. Andrade e Sampaio (2016) realizaram um estudo que concluiu que o consumo de álcool e de drogas por parte de médicos tinha o objetivo de "atenuar as angústias" e que eles, apesar de serem aptos a orientar seus pacientes em relação aos bons hábitos de saúde, eram também incapazes de lidar com seu próprio adoecimento.

Com relação aos aspectos ligados a saúde, a maioria dos médicos indicaram não possuir nenhuma doença $(72,8 \%)$ e $(29,7 \%)$ afirmaram fazer uso de medicamento contínuo. Entre aqueles que afirmaram possuir enfermidades, as mais citadas foram alergias, hipertensão, gastrite e depressão, sendo que as três últimas podem estar relacionadas ao trabalho (MENDES; FERREIRA, 2007; DIAS, 2015; COUTO; COUTO, 2020).

\subsection{Análise e discussão dos indicadores de risco de adoecimento no trabalho}

Os dados a seguir apresentados e discutidos retratam os resultados gerais do estudo, onde constam as dimensões 'Contexto do Trabalho' e os construtos: organização do trabalho, condições do trabalho e relações sócio profissionais; "Custo Humano no Trabalho" e os construtos: custo físico, custo cognitivo e afetivo; 'Vivências de Prazer' e os construtos: realização profissional e liberdade de expressão; 'Vivências de Sofrimento' e os construtos: esgotamento profissional e falta de reconhecimento; 'Danos Relacionados ao Trabalho' e os construtos: dano físico, psicológico e social. Por fim, constam as 'Estratégias de Defesa'.

\subsubsection{Contexto do trabalho}

Os dados obtidos indicaram que 'Organização do Trabalho' obteve média de 2,50, sendo classificada em nível crítico. O construto Organização do Trabalho em nível crítico significa que, em média, os pesquisados avaliaram que a divisão de tarefas e o controle do trabalho não são satisfatórios. Essa conclusão encontra consonância com o observado por Barra (2019) em estudo realizado com médicos no Distrito Federal, onde concluiu que a falta de estruturação do trabalho foi o principal fator percebido como indutor de problemas de saúde mental entre os pesquisados. Ainda em relação a Organização do Trabalho, o citado construto obteve um desvio padrão de 0,72, coeficiente de variação próximo a 30,0\%, mínimo de 1,00 e máximo de 4,91. Esses resultados indicaram que alguns médicos avaliaram esse quesito como satisfatório (médias próximas a 5) ao passo que outros perceberam que este é precário (notas próximas a 1). Esse resultado indicou haver heterogeneidade em relação à percepção dos pesquisados acerca do construto mencionado, conclusão reiterada pela análise de frequência: $(52,9 \%)$ avaliou a Organização do Trabalho como crítica, $(7,0 \%)$ como satisfatória e $(40,1 \%)$, grave.

Quanto às 'Condições de Trabalho', verificou-se média de 2,74, construto também classificado em nível crítico. Portanto, em média, os respondentes avaliaram que a qualidade do ambiente físico do trabalho, no que se refere a equipamentos e materiais, não é satisfatória. A análise de frequência revelou que $(48,1 \%)$ dos respondentes acredita serem críticas às condições de trabalho a que estão submetidos. Somando a essa porcentagem àquela apresentada pela categoria grave $(34,2 \%)$, observa-se que $82,3 \%$ da amostra, portanto a maioria dos pesquisados, não está satisfeita com as condições de trabalho oferecidas nos locais onde laboram. Esse resultado desperta preocupação, sobretudo porque os médicos necessitam de condições adequadas de trabalho para prestar um bom atendimento à população.

Para o construto 'Relações Sócioprofissionais' houve média de 3,30, sendo classificada como crítica. Portanto, em média, os pesquisados avaliaram que as formas de gestão, a comunicação e a interação profissional nos locais de trabalho não são satisfatórias. Esses dados 
estão em consonância com o estudo de Schwartz (2019), em que a relação do médico com a chefia, excesso de burocracia, precariedade na informatização dos processos, normas inadequadas e falta de autonomia em determinadas situações, dificultam a realização do trabalho médico. A análise de frequência indicou os seguintes resultados para as categorias: satisfatória $(36,9 \%)$, enquanto as demais categorias somam $63,1 \%$ (50,4\% para categoria crítico e $12,7 \%$ para a grave).

\subsubsection{Custo humano no trabalho}

Verificou-se média de 2,81 para o construto 'Custo Físico'. O Custo Físico em nível crítico indicou que, em média, os respondentes avaliaram que os danos físiológicos e biomecânicos a que estão submetidos não são satisfatórios. Essa conclusão foi encontrada também em estudo realizado por Pádua e Ferreira (2020) com médicos no Distrito Federal. Os autores concluíram que o desgaste físico, a sobrecarga, a exaustão e o baixo de rendimento no trabalho retratam o real trabalho em emergências médicas, o que expõe a fragilidade destes trabalhadores. Ainda sobre o Custo Físico, o citado construto obteve um desvio padrão de 0,78 , coeficiente de variação de 27,69\%, mínimo de 1,00 e máximo de 5,00. Ainda, a maioria dos respondentes $(68,3 \%)$ avaliou o Custo Físico como crítico, ao passo que outros indicaram ser este grave $(13,0 \%)$ e satisfatório na percepção de $(18,7 \%)$. Diante desses percentuais, se destaca aqueles que avaliaram o Custo Físico como crítico e grave $(81,3 \%)$. Esse fator merece atenção, pois, apresenta potencial de geração de sintomas físicos, influenciando de forma direta e importante a vida profissional e pessoal dos médicos.

No que se refere ao 'Custo Cognitivo', este apresentou a maior média $(M=4,06)$ entre os construtos que formam a dimensão 'Custo Humano no Trabalho'. Essa média é classificada em nível grave. Isso indicou que o esforço intelectual empreendido para aprendizagem, resolução de problemas e demanda de decisão no trabalho é muito elevado. Com o surgimento da pandemia, os médicos tiveram que aprender em "tempo real" a tratar uma nova doença que já causou e vem causando muitas mortes de pacientes e de colegas de trabalho (REGO; PALÁCIOS, 2020). O Custo Cognitivo obteve, ainda, desvio padrão de 0,70 , coeficiente de variação de $17,21 \%$, mínimo de 1,60 e máximo de 5,00. Dentre os construtos da dimensão 'Custo Humano no Trabalho', o Custo Cognitivo foi aquele que apresentou o menor valor de desvio padrão e de coeficiente de variação, o que indicou a concordância que a maioria dos pesquisados tem em relação ao elevado dispêndio intelectual que o exercício da medicina vem exigindo dos médicos neste momento de pandemia.

Em relação ao 'Custo Afetivo', verificou-se média de 2,71 (nível crítico). Esse resultado indicou que, em média, os respondentes avaliaram o dispêndio emocional (sob a forma de reações afetivas e estado de humor) como não satisfatório. Verificou-se, também, que o Custo Afetivo apresentou o menor valor de média $(\mathrm{M}=2,71)$. Esse resultado indicou que, em média, o dispêndio causado por esse tipo de custo foi o que menos atingiu os médicos pesquisados, se levado em consideração os demais construtos inerentes a dimensão 'Custo Humano no Trabalho'.

\subsubsection{Vivências de prazer}

Em relação ao construto 'Realização Profissional', verificou-se média alta de 4,64, classificada em nível satisfatório (TAB. 2). Esse resultado indicou que, em média, os respondentes avaliaram que são satisfatórias as vivências de gratificação profissional, orgulho e identificação com o trabalho que realizam. Esse resultado é coerente com o estudo de Sousa e Costa (2017) realizado com profissionais da área de saúde na cidade de Belo Horizonte/MG. 
Nele, foi identificado que, para os pesquisados, o que deixa a profissão mais prazerosa é o reconhecimento vindo dos pacientes.

Ainda em relação a 'Realização Profissional', verificou-se que o citado construto obteve desvio padrão de 1,26 e coeficiente de variação de 32,93\%. Esses dados indicam que a amostra apresenta certa heterogeneidade em relação ao fator em questão. Para os respondentes que apresentaram médias iguais ou próximas a 0,67 (mínimo observado), a profissão em questão traz pouca realização profissional, enquanto para aqueles que tiveram médias próximas ou iguais a 6,00 (máximo observado), manifestaram que o trabalho que realizam é fonte de valorização e de reconhecimento profissional. A análise de frequência indicou que a maioria dos respondentes $(74,3 \%)$ avaliou a realização profissional como satisfatória, ao passo que outros indicaram ser esta crítica $(20 \%)$ ou grave $(5,7 \%)$. Acerca desses percentuais, chama atenção o número baixo de médicos $(5,7 \%)$ que avaliaram a 'Realização Profissional' como grave. Esse quesito reforça os sentimentos de reconhecimento e de valorização que os profissionais percebem no exercício da profissão.

Em relação ao construto 'Liberdade de Expressão', a média foi de 4,19, também classificado em nível satisfatório. Esse resultado indicou que, em média, os pesquisados avaliaram como adequadas as vivências de liberdade para pensar, para organizar e para falar sobre o trabalho que desempenham. Ainda, 'Liberdade de Expressão' obteve um desvio padrão de 1,38, coeficiente de variação de 32,93\%, mínimo de 0,25 e máximo de 6,00. Verificou-se, portanto, que esse construto, em relação a realização profissional, obteve maior valor de desvio padrão e de coeficiente de variação, o que indicou ser mais heterogênea a percepção dos pesquisados acerca da liberdade de expressão que possuem no ambiente de trabalho em relação à sua realização profissional. $\mathrm{Na}$ análise de frequência foi constatado que a maioria dos respondentes $(66,1 \%)$ avaliou a 'Liberdade de Expressão' como satisfatória, ao passo que outros indicaram ser ela crítica $(24,7 \%)$ ou grave $(9,2 \%)$. Acerca desses percentuais, destacase o número de médicos $(66,1 \%)$ que avaliaram a 'Liberdade de Expressão' como satisfatória, sendo esta, fonte de prazer no trabalho, na visão de Mendes e Ferreira (2007).

\subsubsection{Vivências de sofrimento}

Para o construto 'Esgotamento Profissional', a média foi de 3,98, sendo este classificado em nível crítico. O esgotamento profissional em nível crítico significa que os pesquisados, em média, avaliaram que vivenciam frustração, insegurança, inutilidade, desgaste e estresse em seu ambiente do trabalho. Portanto, ações imediatas em relação a um melhor planejamento das atividades devem ser realizadas por parte das instituições no intuito de se evitar o adoecimento mental. Resultados semelhantes foram encontrados por Junior e Dos Santos Ribeiro (2017) e por Servádio (2019). Os primeiros autores investigaram o prazer e sofrimento durante a formação de residentes na cidade de São Luiz, no Maranhão. Os resultados demonstraram que os pesquisados apresentaram sentimento de desgaste e cansaço que podem estar relacionados à alta carga horária semanal que os residentes precisam cumprir. Em relação a segunda pesquisa, de caráter qualitativo, pesquisou-se residentes médicos com atuação na área de trauma em um hospital público na cidade de Belo Horizonte/MG, cujo foco principal foram as manifestações de estresse, que se mostraram presentes, inclusive, sendo identificado manifestações de ideação suicida. Ainda sobre os resultados relacionados ao Esgotamento Profissional, o citado construto obteve um desvio padrão de 1,55 , coeficiente de variação de 39,02\%, mínimo de 0,00 e máximo de 6,00. Obteve-se menor valor de coeficiente de variação em relação à Falta de Reconhecimento. Portanto, a percepção dos pesquisados quanto ao Esgotamento Profissional ao qual estão submetidos é mais homogêneo em relação à percepção que eles têm quanto à Falta de Reconhecimento. A análise de frequência revelou que a maioria dos respondentes $(62,6 \%)$ acredita vivenciar grave nível de Esgotamento Profissional, ao passo que os demais indicaram 
ser esta crítica $(21,9 \%)$ ou satisfatória $(15,5 \%)$. Acerca desses resultados, ficou evidenciado o esgotamento profissional e a sobrecarga de trabalho em mais de $60 \%$ dos médicos pesquisados.

Quanto à 'Falta de Reconhecimento', verificou-se média baixa de 1,26, sendo esta classificada em nível satisfatório. Esse resultado indicou que, em média, os pesquisados avaliaram que não vivenciam ou pouco vivenciam sentimento de injustiça, indignação e desvalorização pelo não reconhecimento do trabalho realizado. Essa conclusão encontra consonância com o observado em pesquisa realizada por Honório e Simões (2016). Esses autores observaram que as principais causas de prazer entre profissionais da medicina residem no sentimento de realização profissional, de reconhecimento do seu trabalho e na possibilidade de realizar conquistas pessoais. O construto 'falta de reconhecimento' obteve desvio padrão de 1,43, coeficiente de variação acima de 100,00, mínimo de 0,00 e máximo de 6,00. Esses resultados indicam alta heterogeneidade na percepção dos respondentes em relação à falta de reconhecimento em seu ambiente de trabalho. Esse resultado é confirmado pela análise de frequência que constatou que $78,6 \%$ da amostra manifestou possuir baixa percepção de 'falta de reconhecimento', enquanto 21,4 indicaram que percebem esse fator de forma crítica ou grave.

\subsubsection{Danos relacionados ao trabalho}

Em relação aos 'Danos Físicos', a média foi de 2,37, sendo está classificada em nível crítico. Esse resultado indicou que, em média, os respondentes avaliaram que as dores no corpo e os distúrbios biológicos causados pelo trabalho dificultam a realização de suas tarefas. Quando o ambiente de trabalho possui condições desfavoráveis, é possível que os danos físicos se elevem e os indivíduos adoeçam, conforme afirma Torres (2020).

Os resultados relacionados aos 'Danos Físicos' apresentados por meio da TAB. 2, obteve um desvio padrão de 1,26, coeficiente de variação de 53,13\%, mínimo de 0,00 e máximo de 6,00. Esses resultados indicaram que a percepção dos pesquisados a respeito desse construto é heterogênea. Entretanto, a posição dos respondentes é ainda mais diversa em relação a 'Danos Psicológicos' (CV = 99,12) e a 'Danos Sociais' (CV =103,03\%). A análise de frequência mostrou que a maioria dos respondentes $(40,9 \%)$ avaliou como suportável o 'Dano Físico' a que está submetido no trabalho, ao passo que outros indicaram ser este crítico $(35,7 \%)$, grave $(12,5 \%)$ ou indicativo de presença de doenças ocupacionais $(11,0 \%)$.

Em relação aos 'Danos Psicológicos', verificou-se média baixa de 1,49, sendo classificada em nível suportável. Esse resultado indicou que, em média, os médicos manifestaram que os 'Danos Psicológicos' gerados no ambiente de trabalho não são fatores de elevado desgaste mental. Esse construto obteve desvio padrão de 1,48, coeficiente de variação de 99,12\%, mínimo de 0,00 e máximo de 6,00. O elevado valor do coeficiente de variação indicou existência de grande dispersão dos dados em torno da média, isto é, apesar de em média os médicos relatarem não serem demasiadamente relevantes os 'Danos Psicológicos' a que estão submetidos, alguns profissionais entendem ser este um fator importante de desgaste de sua saúde mental no trabalho. Conforme análise de frequência, esses médicos somam 7,7\% da amostra, percentual que manifestaram possuir sensação de vazio, sentimentos de desemparo, abandono, solidão e presença de adoecimento mental que vem ocorrendo pelo trabalho realizado. Por outro lado, 68,8\% indicaram que o nível de 'Dano Psicológico' a que estão submetidos é suportável.

Em relação ao 'Dano Social', a média foi de 1,35, classificada como suportável. Esse resultado indicou que, em média, os pesquisados acreditam que os 'Danos Sociais' a que estão submetidos não são elementos que geram alta disfunção em relação à saúde mental no trabalho. Esse ponto, portanto, repercute de forma positiva nos aspectos sociais da vida dos pesquisados. 


\subsubsection{Estratégias de defesa}

Em relação às 'Estratégias de Defesa', verificou-se média de 3,18, sendo esta classificada em nível intenso como pode ser observado com base nos dados apresentados por meio da TAB 2. Esse resultado indicou que, em média, os respondentes utilizam intensamente as estratégias de defesa que podem minimizar ou eliminar os riscos de adoecimento mental, sobretudo, como a utilização da experiência profissional na solução de dificuldades e tensões excessivas no trabalho e a possibilidade cooperação entre os pares.

Em estudo de Pádua e Ferreira (2020), as estratégias de defesa identificadas foram classificadas em dois eixos: 44,6\% dos pesquisados utilizam de apoio dos colegas de trabalho, familiares e de amigos e 55,4\% utilizam de estratégias fora do trabalho como atividades físicas, fazer o de que gosta e a busca de experiências religiosas.

Ainda sobre os resultados relacionados à Dimensão 'Estratégias de Defesa', a citada dimensão obteve um desvio padrão de 0,69 , coeficiente de variação de $21,82 \%$, mínimo de 1,00 e máximo de 5,00. Esses resultados mostram que a percepção dos pesquisados acerca da utilização de estratégias de defesa tende para a homogeneidade. Aproximadamente um terço dos respondentes $(37,2 \%)$ avaliou as Estratégias de Defesa como moderada, ao passo que outros $36,2 \%$ indicaram ser esta intensa e 13,5\% muito intensa (13,5\%). Dessa forma, de acordo com os resultados obtidos a maioria dos pesquisados $(86,9 \%)$ utilizam das Estratégias de Defesa para minimizar ou eliminar os riscos de adoecimento mental no trabalho. Portanto, ficou evidenciado que por meio das Estratégias de Defesa, os médicos vêm lidando com as situações de sofrimento e as transformam, de alguma forma, em prazer, buscando o equilíbrio para a sua saúde mental e qualidade de vida.

\section{Conclusões}

Este estudo atingiu seu objetivo ao descrever a percepção do risco de adoecimento mental de médicos que atuam em serviços de saúde considerando a COVID-19 no estado de Minas Gerais, tendo como referência a psicodinâmica do trabalho.

Em termos metodológicos, o estudo foi descritivo, de abordagem quantitativa, em uma população de 54.393 médicos, com amostra calculada de 401 sujeitos ( $\mathrm{p}<0,005)$.

Os resultados da pesquisa indicaram que o Contexto e o Custo humano do trabalho foram identificados como fontes causadoras de sofrimento, evidenciados pela classificação 'crítica/grave' que receberam em todos os domínios avaliados, sendo a 'organização do trabalho' a dimensão mais crítica. As relações sócioprofissionais apresentaram certa divergência no contexto laboral pesquisado, uma vez que, por um lado, os médicos mencionaram a comunicação insatisfatória, a existência de disputas profissionais e a falta integração e confiança entre os colegas, e, por outro lado, manifestaram ter a cooperação e solidariedade no desenvolvimento das atividades, aspectos estes que necessitam maior aprofundamento em pesquisas futuras.

Identificou-se que os médicos experimentam tanto o sentimento de prazer quanto de sofrimento na realização das atividades profissionais, sofrendo com o contexto e as exigências do trabalho, o que vem levando ao esgotamento profissional identificado em grau 'grave/crítico'. Observou-se ainda, que a realização profissional e a liberdade de expressão são fontes de prazer no trabalho, tendo sido avaliado em grau satisfatório.

Quanto aos danos relacionados ao trabalho, os pesquisados não foram identificados em relação ao sofrimento com os danos físicos, psíquicos e sociais, podendo ser considerado 'satisfatório' em relação a estes fatores. Nesse contexto, a pesquisa permitiu observar que as dores no corpo, braços, costas, pernas apresentaram médias compatíveis com risco suportável, portanto, a maior exigência está sendo em relação ao custo físico se comparado aos demais. 
A utilização das estratégias de defesa para eliminar ou minimizar o risco de adoecimento mental foram utilizadas pela grande maioria dos pesquisados. As principais estratégias identificadas estão relacionadas à utilização de experiência pessoal na solução de dificuldades e tensões excessivas no trabalho; possibilidade de canal aberto nas instituições de saúde para discussão das situações de maior dificuldade e tensão, buscando a utilização dos protocolos mais indicados para os atendimentos; e a cooperação entre os colegas no compartilhamento das dificuldades relacionadas ao trabalho, principalmente, na discussão dos casos mais complexos, envolvendo a Covid.

Em termos de contribuições deste estudo, pode-se citar: a utilização do ITRA juntamente com a Escala de Estratégias de Defesa para avaliação da saúde mental de médicos, sobretudo num momento especial em que ocorre a pandemia COVID-19; oferecimento de subsídios para instituições de saúde promoverem a revisão de suas políticas de gestão de pessoas para a categoria médica de modo a proporcionar-lhes uma melhor qualidade de vida no trabalho com destaque para a reavaliação da carga horária de trabalho que ultrapassa os limites físicos e psíquicos suportados por estes profissionais; proposição de alternativas que criem ações que estimulem a qualidade de vida dos médicos e proporcione um ambiente saudável com uma ergonomia adequada; além da ampliação dos canais de comunicação para amenizar e/ou eliminar as fontes de tensão excessiva indutora dos quadros de riscos de adoecimento mental observado na categoria avaliada, o que refletirá em um melhor atendimento a sociedade.

Por fim, como limitação do estudo aponta-se a não utilização da abordagem qualitativa concomitante a quantitativa, como sugerida pelos autores do ITRA, o que poderia ter contribuído para aprofundar os resultados obtidos em relação às vivências relacionadas à saúde mental dos médicos pesquisados. No entanto, em função da própria Pandemia e das medidas de combate, sobretudo, em relação ao isolamento social, não foi possível à realização das entrevistas, necessárias para o desenvolvimento da abordagem qualitativa, o que se torna uma proposição para os futuros estudos com esta categoria profissional e demais profissionais que atuam na área da saúde, diante da Pandemia COVID-19, que ainda se apresenta como crítica em todo o mundo. Os dados globais em meados de Julho/2021 são os seguintes: no mundo são 187.296.646 de casos com 4.046.470 óbitos; no Brasil 19,2 milhões de casos com 536 mil óbitos; e no estado de Minas Gerais 1,87 milhão de casos com 48.151 óbitos (WHO, COVID19, 2021; MINAS GERAIS, 2021). 


\section{REFERÊNCIAS}

ANDRADE, João Brainer Clares de; SAMPAIO, José Jackson Coelho. O médico e o estudante de medicina: quando eles precisam de ajuda. Fortaleza: EdUECE, 2016. 342 p.

BARNETT, Vic. Sample survey principles and methods. 2. ed. Londres: Arnold, 1991.

BARRA, Marcello Cavalcanti. Percepções de médicos e médicas da emergência pediátrica de um hospital no Distrito Federal sobre problemas de saúde mental na categoria médica de Brasília. 2019. 300 f. Tese (Doutorado em Sociologia). Universidade de Brasília, Brasília, 2019.

BRASIL. Ministério da Saúde. Entenda a diferença entre Coronavírus, Covid-19 e Novo Coronavírus. 2020. Disponível em: https://www.gov.br/pt-br/noticias/saude-evigilancia-sanitaria/2020/03/entenda-a-diferenca-entre-coronavirus-covid-19-e-novocoronavirus. Acesso em: 13 abr. 2020.

BRASIL. Casa Civil. Saúde mental: pesquisa analisa impacto psicológico do enfrentamento à Covid-19 em profissionais da saúde. Brasília. 2020. Disponível em https://www.gov.br/casacivil/pt-br/assuntos/noticias/2020/julho/saude-mental-pesquisaanalisa-impacto-psicologico-do-enfrentamento-a-covid-19-em-profissionais-da-saude. Acesso em: 29 set. 2020.

CHEN, Qiongni; LIANG, Mining; LI, Yamin; GUO, Jincai; FEI, Dongxue; WANG, Ling; HE, Li; SHENG, Caihua; CAI, Yiwen; LI, Xiaojuan. Mental health care for medical staff in China during the COVID-19 outbreak. The Lancet Psychiatry,

COUTO, Hudson Araújo; COUTO, Dennes. Carvalho. Ergonomia 4.0: dos conceitos básicos à $4^{\mathrm{a}}$ revolução industrial. Belo Horizonte: Ergo, 2020.

CRODA, Júlio; OLIVEIRA, Wanderson Kleber de; FRUTUOSO, Rodrigo Lins; MANDETTA, Luiz Henrique; BAIA-DA-SILVA, Djane Clarys; BRITO-SOUSA, José Diego; MONTEIRO, Wuelton Marcelo; LACERDA, Marcus Vinícius Guimarães. COVID-19 in Brazil: advantages of a socialized unified health system and preparation to contain cases. Revista da Sociedade Brasileira de Medicina Tropical, v. 53, p. 1-6, 2020.

DA CUNHA, Mayara Rodrigues. Psicodinâmica do trabalho de médicos oncologistas: vivências de prazer e sofrimento em instituições hospitalares da cidade de Belo Horizonte. Horizontes Interdisciplinares da Gestão, v. 4, n. 1, p. 84-104, jan./jun. 2019.

DEJOURS, Christophe. Repressão e subversão em psicossomática. Rio de Janeiro: Zahar, v. 7, 1991.

DEJOURS, Christophe; ABDOUCHELI, Elisabeth; JAYET, Christian. Psicodinâmica do trabalho: contribuições da escola dejouriana à análise da relação prazer e sofrimento no trabalho. São Paulo: Atlas S.A, 1994.

DEJOURS, Christophe. Subjetividade, trabalho e ação. Production, v. 14, n. 3, p. 27 34, dez. 2004.

DEJOURS, Christophe. A saúde mental entre impulsos individuais e requisitos coletivos (sublimação e trabalho). In: LACMAN, Selama; SZNELWAR, Larte Idal. (Orgs.). Christophe Dejours: da psicopatologia à psicodinâmica do trabalho. 3. Ed. Rio de Janeiro: Fiocruz, 2011.

DEJOURS, Christophe. El sufrimiento en el trabajo. Argentina, Buenos Aires: Editorial Topia, 2015.

DEJOURS, Christophe. Psicodinâmica do trabalho: casos clínicos. Porto Alegre: Dublinense, 2017.

DIAS, Elizabeth Costa. Condições de trabalho e saúde dos médicos: uma questão negligenciada e um desafio para a Associação Nacional de Medicina do Trabalho. Revista Brasileira de Medicina do Trabalho, v. 13, n. 2, p. 60-68, 2015. 
FERREIRA, Mário César; MENDES, Ana Magnólia. Trabalho e riscos de adoecimento: o caso dos auditores-fiscais da previdência social brasileira. Brasília, DF: Edições Ler, Pensar, Agir (IPA), 2003.

GLANZNER, Cecília Helena; OLSCHOWSKY, Agnes; DAL PAI, Daiane; TAVARES, Juliana Petri; HOFFMAN, Deisi Angélica. Avaliação de indicadores e vivências de prazer/sofrimento em equipes de saúde da família com o referencial da Psicodinâmica do Trabalho. Revista Gaúcha de Enfermagem, v. 38, n. 4, jun. 2017.

GRACINO, Mariana Evangelista; ZITTA, Ana Laura Lima; MANGILI, Otavio Celeste; MASSUDA, Ely Mitie. A saúde física e mental do profissional médico: uma revisão sistemática. Saúde em Debate, v. 40, n. 110, p. 244-263, jul./set. 2016.

GREENLAND, John R.; MICHELOW, Marilyn D.; WANG, Linlin; LONDON, Martin J. COVID-19 Infection: Implications for Perioperative and Critical Care Physicians. Anesthesiology, v. 27, n. 10, p. 1-16, jun. 2020.

HAIR JUNIOR, Joseph F.; ANDERSON, Rolph E.; TATHAM, Ronald L.; BLACK, William C. Análise multivariada de dados. 5. ed. Porto Alegre: Bookman, 2005.

HONÓRIO, Luiz Carlos; SIMÕES, Diana Alves Prates. Prazer e sofrimento no trabalho de médicos oncologistas: estudo em uma clínica hospitalar mineira. In: SIMPÓSIO DE EXCELÊNCIA EM GESTÃO E TECNOLOGIA (SEGET), 13, 2016, Resende, RJ. Resende: Associação Educacional Dom Bosco, 2016. Disponível em: https://www.aedb.br/seget/arquivos/artigos16/23024230.pdf. Acesso em 23 de ago. 2020.

JUNIOR, Nelson Silva Rodrigues; DOS SANTOS RIBEIRO, Carla Vaz. Psicodinâmica do trabalho: a dialética do prazer e sofrimento em residentes multiprofissionais de um hospital de ensino. Tempus Actas de Saúde Coletiva, v. 11, n. 3, p. ág. 193-215, 2017.

LAI, Chih-cheng; SHIH, Tzu-ping; KO, Wen-chien; TANG, Hung-jen; HSUEH, Poren. Severe acute respiratory syndrome coronavirus 2 (SARS-CoV-2) and coronavirus disease2019 (COVID-19): The epidemic and the challenges. International Journal of Antimicrobial Agents, v. 55, n. 3, p. 1-6, mar. 2020.

LU, Wen; WANG, Hang; LIN, Yuxing; LI, Li. Psychological status of medical workforce during the COVID-19 pandemic: A cross-sectional study. Psychiatry research, $\mathrm{p}$. $112936,2020$.

MACIEL, Regina Heloisa; SANTOS, João Bosco Feitosa dos; SALES, Telma Bessa; ALVES, Marco Aurélio de Andrade; LUNA, Ana Paula; FEITOSA, Leonardo Bezerra. Multiplicidade de vínculos de médicos no Estado do Ceará. Revista de Saúde Pública, v. 44, n. 5, p. 950-956, 2010.

MÉLOU, Ana Carolina Secco Andrade; OLIVEIRA Paulo de Tarso Ribeiro; SILVA, Anaclan Pereira Lopes; CARDOSO, Márcia Roberta de Oliveira. A psicodinâmica do trabalho: principais contribuições ao seu delineamento. Ayvu: Revista de Psicologia, v.4, n.1, 2017.

MENDES, Ana Magnólia, FERREIRA, Mário César, FACAS, Emílio Peres; VIEIRA, Adriano Pinho. Validação do Inventário de Trabalho e Riscos de Adoecimento - ITRA. In: IV CONGRESSO DE PSICOLOGIA NORTE-NORDESTE, 2005, Anais ... Salvador: UFBA, 2005.

MENDES, Ana Magnólia; FERREIRA, Mário César. Inventário sobre trabalho e adoecimento-ITRA: Instrumento auxiliar de diagnóstico de indicadores críticos no trabalho. In: MENDES Ana Magnólia. (Org.). Psicodinâmica do trabalho: teoria, método e pesquisas. São Paulo: Casa do Psicólogo, 2007. Cap. 5, p. 111-22,

MENDES, Ana Magnólia. Novas formas de organização do trabalho, ação dos trabalhadores e patologias sociais. In: MENDES, Ana Magnólia (org.). Psicodinâmica do trabalho: teoria, método e pesquisas. São Paulo: Casa do Psicólogo, 2007. Cap. 2. p. 49-61.

MESQUITA, José Marcos Carvalho de. Estatística multivariada aplicada à administração. Curitiba: Editora CRV, 2010. 
MINAS GERAIS. Secretaria de Estado de Saúde (SESMG). Centro De Operações De Emergência Em Saúde Pública. Cenário em Minas Gerais: COVID-19 Coronavírus. 2020a. Disponível em: http://coronavirus.saude.mg.gov.br/images/boletim/06-junho/2506_Boletim_Epidemiologico_COVID-19.pdf. Acesso em: 27 jun. 2020.

MINAS GERAIS. Secretaria De Estado de Saúde de Minas Gerais (SESMG). Confirmação do primeiro caso de Coronavírus (Covid-19) em Minas Gerais. 2020c. Disponível em: https://www.saude.mg.gov.br/component/gmg/story/12233-confirmacao-doprimeiro-caso-de-coronavirus-covid-19-em-minas-gerais. Acesso em: 27 jun. 2020.

MINAS GERAIS. Secretaria de Estado de Saúde (SESMG). Centro De Operações De Emergência Em Saúde Pública. Cenário em Minas Gerais: COVID-19 Coronavírus. 2021. Disponível em: http://coronavirus.saude.mg.gov.br/images/1-2021/7-julho/COVID-19BOLETIM20210713. pdf. Acesso em: 14 jul. 2021.

ORGANIZAÇÃO MUNDIAL DA SAÚDE (OMS). Relatório mundial de saúde, 2006: trabalhando juntos pela saúde. Brasília, DF: Ministério da Saúde, 2007. Disponível em: <https://www.who.int/whr/2006/06_overview_pr.pdf?ua=1>. Acesso em: 15 abr 2020.

PÁDUA, Leandro Silva; FERREIRA, Mário César. Avaliação do custo humano do trabalho e das estratégias de mediação dos médicos de uma unidade de pronto atendimento. Trabalho (En) Cena, v. 5, n. 1, p. 28-52, 2020.

PITTA, Ana. Hospital: dor e morte como ofício. 5. ed. São Paulo: Hucitec, 2003.

PRESTES, Francine Cassol. Danos à saúde dos trabalhadores de enfermagem em hemodiálise. 2011. 218f. Dissertação (Mestrado em Enfermagem). Santa Maria: Universidade Federal de Santa Maria, 2011.

REGO, Sérgio; PALÁCIOS, Marisa. Saúde mental dos trabalhadores de saúde em tempos de coronavírus. Rio de Janeiro: Fundação Oswaldo Cruz, 2020. Disponível em: https://www.arca.fiocruz.br/bitstream/icict/40659/2/Sa\%c3\%badeMental.PDF. Acesso em: 01 abr. 2020.

SEVÁDIO, Aparecido Donizete. Estresse ocupacional: estudo com residentes médicos do serviço de urgência e emergência cirúrgica em um hospital público na cidade de Belo Horizonte/MG. Belo Horizonte: Curso de Mestrado Acadêmico em Administração do Centro Universitário Unihorizontes, 2019.

SCHWARTZ, Leolei. Estilo de vida e burnout médico no Brasil. Medscape, 2019. Disponível em: http://portugues.medscape.com/slideshow/65000099. Acesso em: 2 jul. 2019.

SOUSA, Caissa Veloso; COSTA, Patrícia Bruna. Prazer e sofrimento no trabalho: Um estudo de caso com profissionais da enfermagem de um hospital privado de Belo Horizonte. Revista de Administração do UNIFATEA, v. 14, n. 14, 2017.

TORRES, Thaís Pinto da Rocha. Prazer, sofrimento e retaliação: um estudo com jovens trabalhadores de Belo Horizonte (MG). 2020. 158f. Dissertação (Mestrado em Adminstração). Faculdade de Ciências Econômicas. Belo Horizonte: Universidade de Minas Gerais, 2020. Disponível em: https://repositorio.ufmg.br/handle/1843/32652. Acesso em: 25 de ago. 2020.

VELAVAN, Thirumalaisamy P.; MEYER, Christian G. The COVID-19 epidemic. Tropical medicine \& international health, v. 25, n. 3, p. 278, mar. 2020. Editoral.

WORLD HEALTH ORGANIZATION (WHO). Middle East respiratory syndrome coronavirus (MERS-CoV). 2020. Site da Organização Mundial da Saúde dedicado a informações sobre a Síndrome Respiratória Grave. Disponível em: https://www.who.int/emergencies/mers-cov/en/. Acesso em: 01 abr. 2020.

WORLD HEALTH ORGANIZATION (WHO). Middle East respiratory syndrome coronavirus (MERS-CoV). 2021. Site da Organização Mundial da Saúde dedicado a informações sobre a Síndrome Respiratória Grave. Disponível em: https://www.who.int/emergencies/mers-cov/en/. Acesso em: 14 jul. 2021. 
ZHANG, Chenxi; YANG, Lulu; LIU, Shuai; MA, Simeng; WANG, Ying; CAI, Zhongxiang; DU, Hui; LI, Ruiting; KANG, Lijun; SU, Meilei. Survey of Insomnia and Related Social Psychological Factors Among Medical Staff Involved in the 2019 Novel Coronavirus Disease Outbreak. Frontiers In Psychiatry, v. 11, p. 1-9, 14 abr. 2020.

ZILLE, Luciano Pereira. Novas perspectivas para a abordagem do estresse ocupacional em gerentes: estudo em organizações brasileiras de setores diversos, 2005. 307f. Tese (Doutorado em Administração), Centro de Pós-graduação e Pesquisas em Administração (CEPEAD). Belo Horizonte: Universidade Federal de Minas Gerais, 2005. Disponível em: http://cepead.face.ufmg.br/btd/files/165/aid165n2a1.pdf. Acesso em: 01 abr. 2020. 